
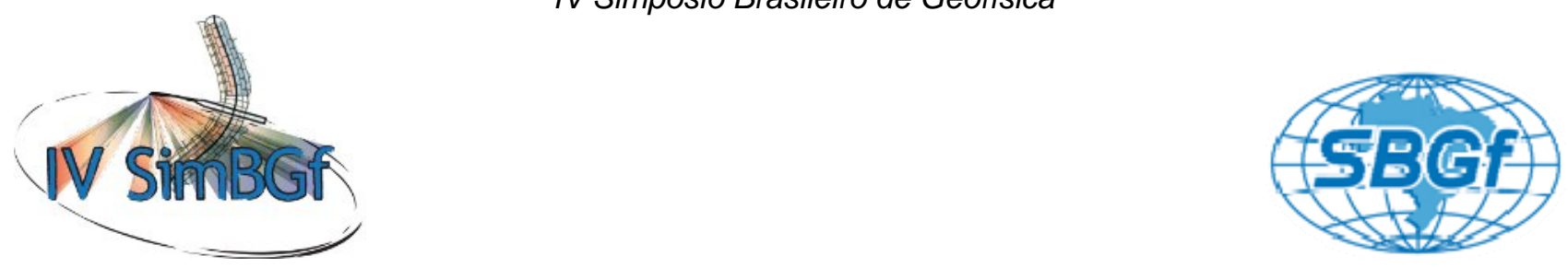

\title{
Correlação indireta entre parâmetros físicos com dados de Tomografia Elétrica na Jazida de Bauxita de Barro Alto - Goiás
}

Leandro Rocha Scislewski, Antônio Tadeu Corrêa Veiga, Gustavo Alves Guerra, Luciano Soares da Cunha, Welitom

Rodrigues, Marcelo Peres Rocha, Mineradora Santo Expedito

Copyright 2008, SBGf - Sociedade Brasileira de Geofísica

Este texto foi preparado para a apresentação no IV Simpósio Brasileiro de Geofísica, Belém, 14 a 17 de novembro de 2010. Seu conteúdo foi revisado pelo Comitê Técnico do IV SimBGf, mas não necessariamente representa a opinião da SBGf ou de seus associados. É proibida a reprodução total ou parcial deste material para propósitos comerciais sem prévia autorização da SBGf.

\section{Resumo}

A jazida de bauxita de Barro Alto, Goiás, é caracterizada como a primeira jazida de bauxita revelada no CentroOeste. Resulta do intemperismo de anortositos do Complexo Máfico-Ultramáfico de Barro Alto. Este estudo preliminar correlacionou-se dados de levantamento geofísico utilizando o método elétrico de Caminhamento Elétrico (Tomografia Elétrica). O objetivo é ressaltar a diversidade da tipologia do minério e do substrato rochoso.

\section{Introdução}

A jazida de bauxita de Barro Alto, inserida na região central do estado de Goiás, é caracterizada como a primeira jazida de bauxita revelada no Centro-Oeste, aflorante em grande extensão, em contexto acessível e geologicamente conhecido. Resultado do intemperismo de anortositos do Complexo Máfico-Ultramáfico de Barro Alto, a jazida tem qualidades físicas, químicas e morfológicas excepcionais, e seu aproveitamento certamente terá impactos positivos em âmbito regional e nacional.

Neste estudo preliminar tentou-se correlacionar dados de densidade, porosidade e permeabilidade com levantamento geofísico utilizando o método elétrico de Caminhamento Elétrico (Tomografia Elétrica). A diversidade da tipologia do minério enfocado é o alvo de pesquisa para a correlação com os estudos de geofísica terrestre.

Abrange os municípios de Barro Alto e Santa Rita do Novo Destino, conforme ilustrado na Figura 1.

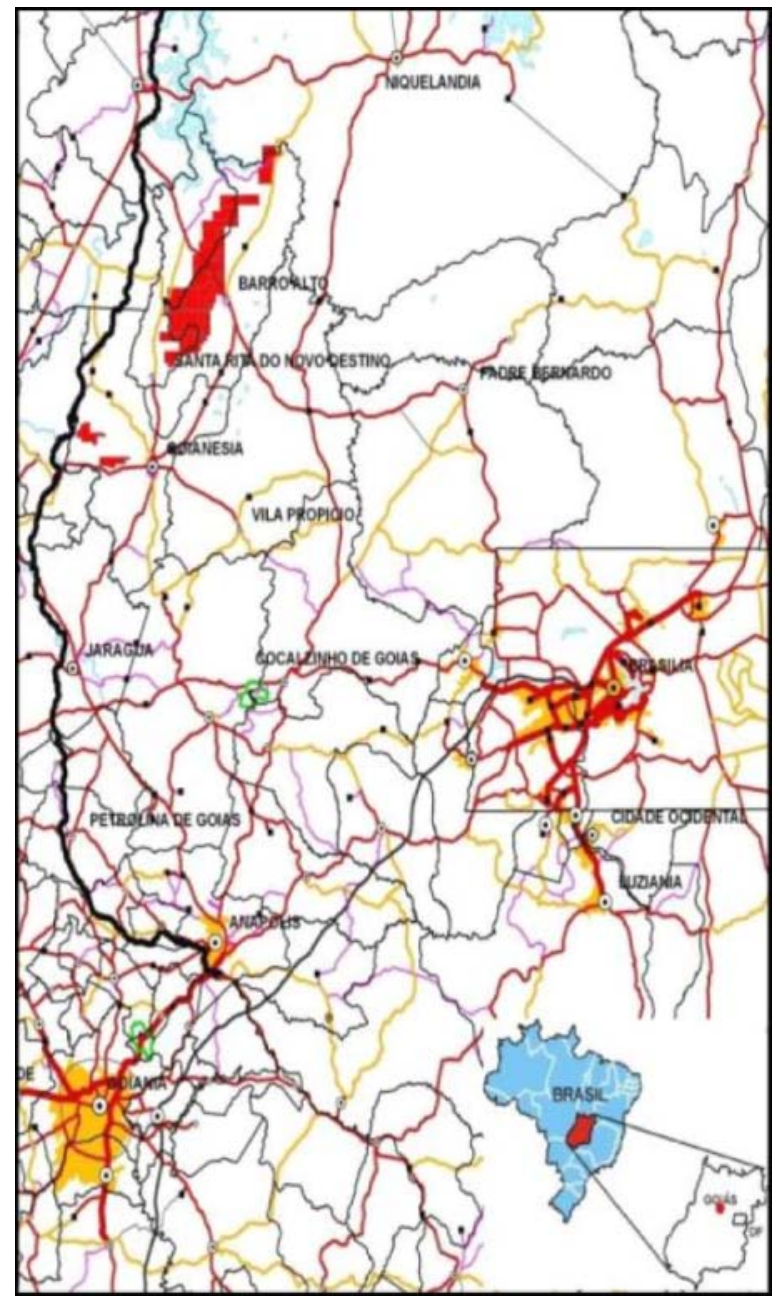

Figura 1-Mapa de localização e

\section{Metodol\&gfaP Problema Investigado}

A região estudada se insere na Província do Tocantins, domínio geotectônico situado entre os crátons do São Francisco e Amazônico (Almeida, 1977). Localiza-se na porção setentrional do Complexo de Barro Alto, um grande corpo máfico-ultramáfico acamadado, tectonicamente posicionado na Faixa Dobrada Brasília, que assinala a zona de interação entre os crátons (Veiga, 2002). 
Abrange anortositos, gabros e piroxenitos, que integram a Série Superior do complexo. Afloram a oeste de rochas ultramáficas que compõem sua Série Inferior. O intemperismo dos anortositos resulta em saprolitos francamente aluminosos, expostos em terrenos elevados. Tais saprolitos constituem o jazimento de bauxita ora estudado.

O Complexo de Barro Alto tem cerca de $150 \mathrm{~km}$ de extensão. Conforme ilustrado na Figura 2, é formado por dois segmentos tectonicamente justapostos: um segmento meridional com direção aproximada E-W; outro setentrional, disposto segundo NNE-SSW (Oliveira, 1993; Ferreira Filho, 1998; dentre outros).

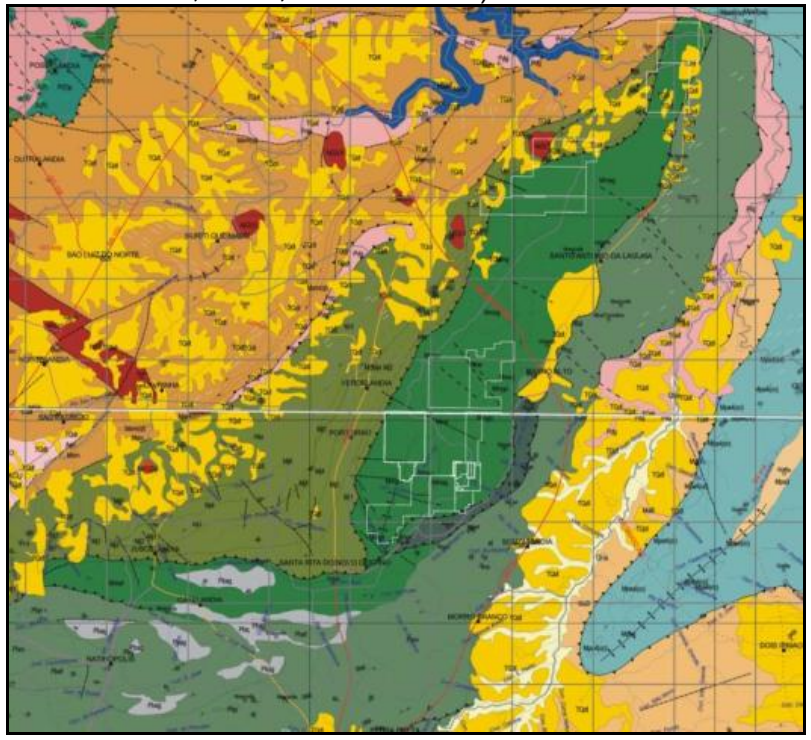

Figura 2 - Mapa geológico regional

O segmento setentrional é delimitado por importantes zonas de cisalhamento: no extremo norte, a estruturação NNE-SSW é truncada por falhas transcorrentes direcionadas segundo E-W; enquanto no extremo sul, o truncamento das estruturas coincide com a movimentação transcorrente do segmento meridional. A leste faz contato com uma faixa de gnaisses miloníticos. A oeste faz contato tectônico com a Seqüência Juscelândia.

Amostras examinadas de anortositos ao microscópio revelaram a seguinte composição mineralógica do protólito de bauxita:

\begin{tabular}{lc}
\hline Hherais & Proporgão estimada \\
\hline Plagioclásio & 80 a $85 \%$ \\
Homblenda e Augita & 5 a $10 \%$ \\
Granada & até $5 \%$ \\
Escapolita & até $5 \%$ \\
Opacos & $<1 \%$ \\
\hline
\end{tabular}

À maneira da controvérsia sobre a origem, persistem incertezas quanto à idade do complexo. Pimentel et al. (2000) interpretaram os três grandes complexos máficoultramáficos como representantes de um terreno exótico, acrescido à Faixa Brasília ao final do Neoproterozóico.
Foi realizado um levantamento geofísico utilizando o método elétrico de Caminhamento Elétrico nas proximidades dos pontos de amostragem de poços destinados ao cálculo de densidade. Essa caracterização geoelétrica teve como principal objetivo determinar a possível presença de zonas argilosas e o topo da rocha sã, assim como a relação dos diversos tipos de bauxita existentes na jazida (maciça e porosa). Ressalta-se que o termo argiloso nesse texto segue a conceituação prospectiva de bauxita que engloba todo material com conteúdo entre o intervalo de alumínio < $40 \%$ e sílica $>$ $5 \%$. Os resultados aqui apresentados foram obtidos nas linhas denominadas EW e NS, com 300 m de extensão cada linha de tomografia elétrica. Nesse levantamento geofísico foi utilizado um espaçamento entre os eletrodos de 5,0m com o objetivo de obter leituras em cerca de 30 níveis. O equipamento utilizado foi o Eletrorrestivímetro Syscal Pro com 8 canais e 60 eletrodos (Iris Instr.).

O processamento dos dados de caminhamento elétrico foi executado com a elaboração de perfis de resistividade aparente. Através desses perfis foi possível identificar, através da projeção na superfície do terreno, as anomalias geofísicas. As figuras em anexo apresentam os produtos obtidos em que foi possível identificar algumas zonas anômalas condutivas relacionadas a regiões de baixo conteúdo de alumínio e zonas anômalas resistivas em superfície associadas a bauxita e zonas anômalas resistivas em profundidade relacionadas ao topo da rocha sã.

\section{Resultados}

Os resultados obtidos a partir do processamento dos dados levantados em campo estão apresentados na forma de seções de tomografia elétrica onde a escala de cores varia do azul (mais condutivo) ao vermelho (mais resistividade).

Para efeito comparativo cada linha está apresentada com seu resultado após processamento, com as anomalias com menores resistividades (baixo alumínio), anomalias resistivas mais superficiais (bauxita) e anomalias resistivas em profundidade (topo da rocha sã), além dos logs de sondagem rotativa dos poços existentes no local do levantamento.

É importante ressaltar que a opção de comparar o resultado da tomografia elétrica com os logs de sondagem ao invés das seções geológicas ocorreu porque essas últimas são produtos de interpretações de poços que distam 50m, ou seja, existe um forte componente informal, na elaboração das seções em uma região com grande variação lateral em profundidade.

No geral, as regiões superficiais das seções geoelétricas e a parte mais basal investigada apresentam as maiores resistividades vinculadas ao material desagregado extremamente insaturadas em água e às rochas sãs. Já lateralmente, as variações das resistividades delimitam, em ambos os perfis, zonas anômalas (resistividades intermediárias) que podem ser associadas à bauxita e as 
zonas anômalas (resistividades baixas) que podem ser associadas a material argiloso.

$\mathrm{Na}$ análise dos resultados foi considerado que as seções apresentadas são produtos do processamento de dados obtidos a partir de um levantamento em superfície, ou seja, não se trata de um método de investigação direta, como sondagens e trincheiras e sim um método de visualização indireta das propriedades físicas do subsolo intrínsecas (composição mineralógica, estruturas e compactação/desagregação quanto propriedades sazonais como o conteúdo de água.

Dessa forma, durante processo interpretativo e a conseqüente delimitação das zonas anômalas deve-se observar um erro inerente ao processo com relação à profundidade obtida para os alvos que varia de $10 \%$ da profundidade máxima nas porções planas e de 15\% nas regiões com relevo acentuado.

As seções apresentadas em anexo devem ser integradas de uma forma coerente com os resultados de informações obtidas em outras formas de investigação, possibilitando assim uma completa integração de dados.

No perfil NS podem ser várias zonas anômalas de baixas resistividades mais localizadas na parte norte e central, com zonas anômalas de alta resistividades concentradas na parte sul.
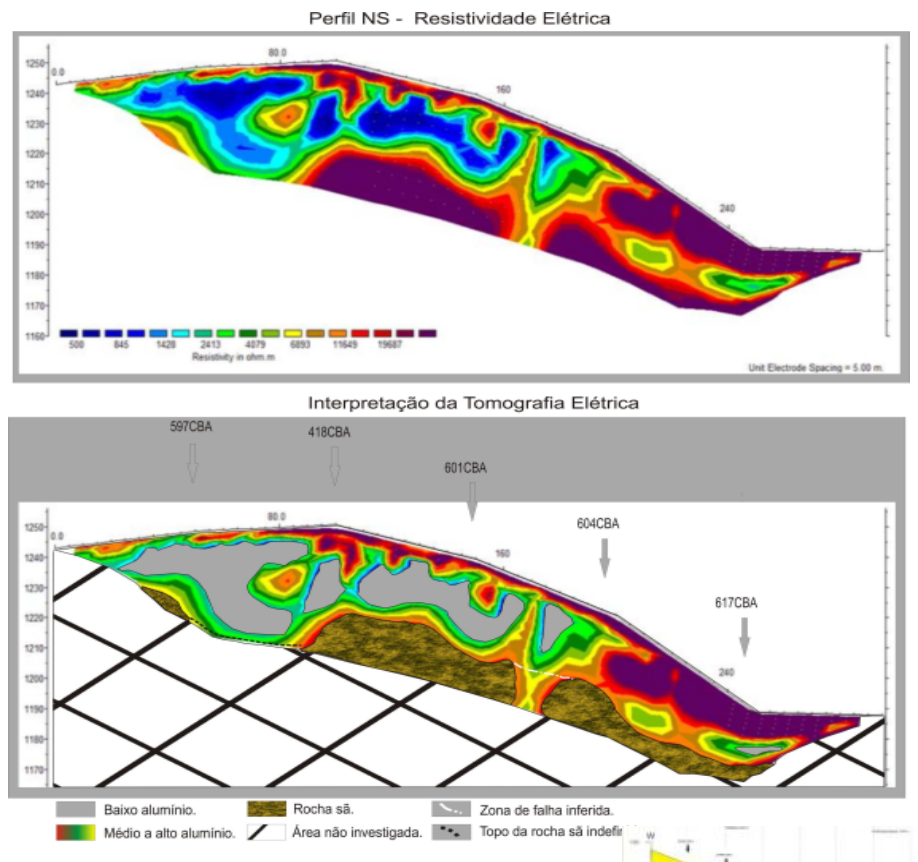

Log de Sondagem Rotativ

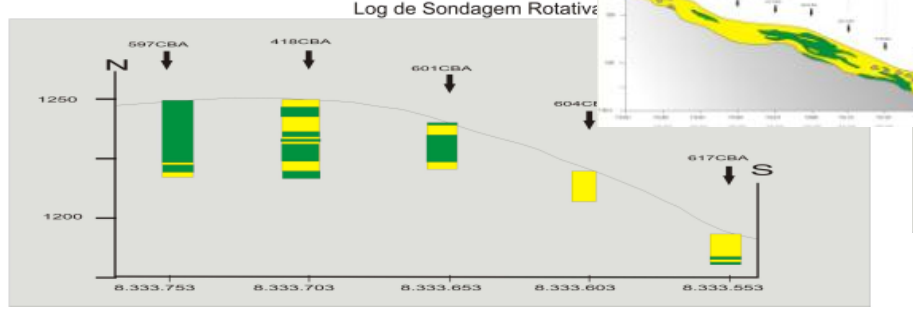

Figura 3 - Perfil NS

IV Simpósio Brasileiro da SBGf - Brasília 2010
O topo da rocha sã está bem delimitado em todo o perfil com exceção da região centrada na posição 60 devido à profundidade de investigação ter sido subestimada. Já na posição 170 a resposta geoelétrica obtida indica uma possível zona de falha.

Comparando o perfil geoelétrico interpretado com os logs dos poços é notado uma boa e coerente correlação com relação à delimitação das zonas de baixo alumínio (argilosas) e quanto à determinação do topo da rocha sã, principalmente nas porções centrais e norte.

$\mathrm{Na}$ parte sul os logs dos poços 604CBA e 617CBA apontam um topo da rocha sã raso $(8,0 \mathrm{~m}$ e $13,0 \mathrm{~m})$ que coincide no perfil geofísico com um início de anomalia de alta resistividade, mas na posição do 604CBA essa anomalia em profundidade diminui sua resistividade caracterizando uma provável desagregação da rocha sã.

No perfil EW as zonas anômalas de baixas resistividades (baixo alumínio) estão mais localizadas na parte central e leste, com zonas anômalas de altas resistividades concentradas na parte oeste. No início e fim do perfil concentram-se as zonas resistivas associadas à bauxita.
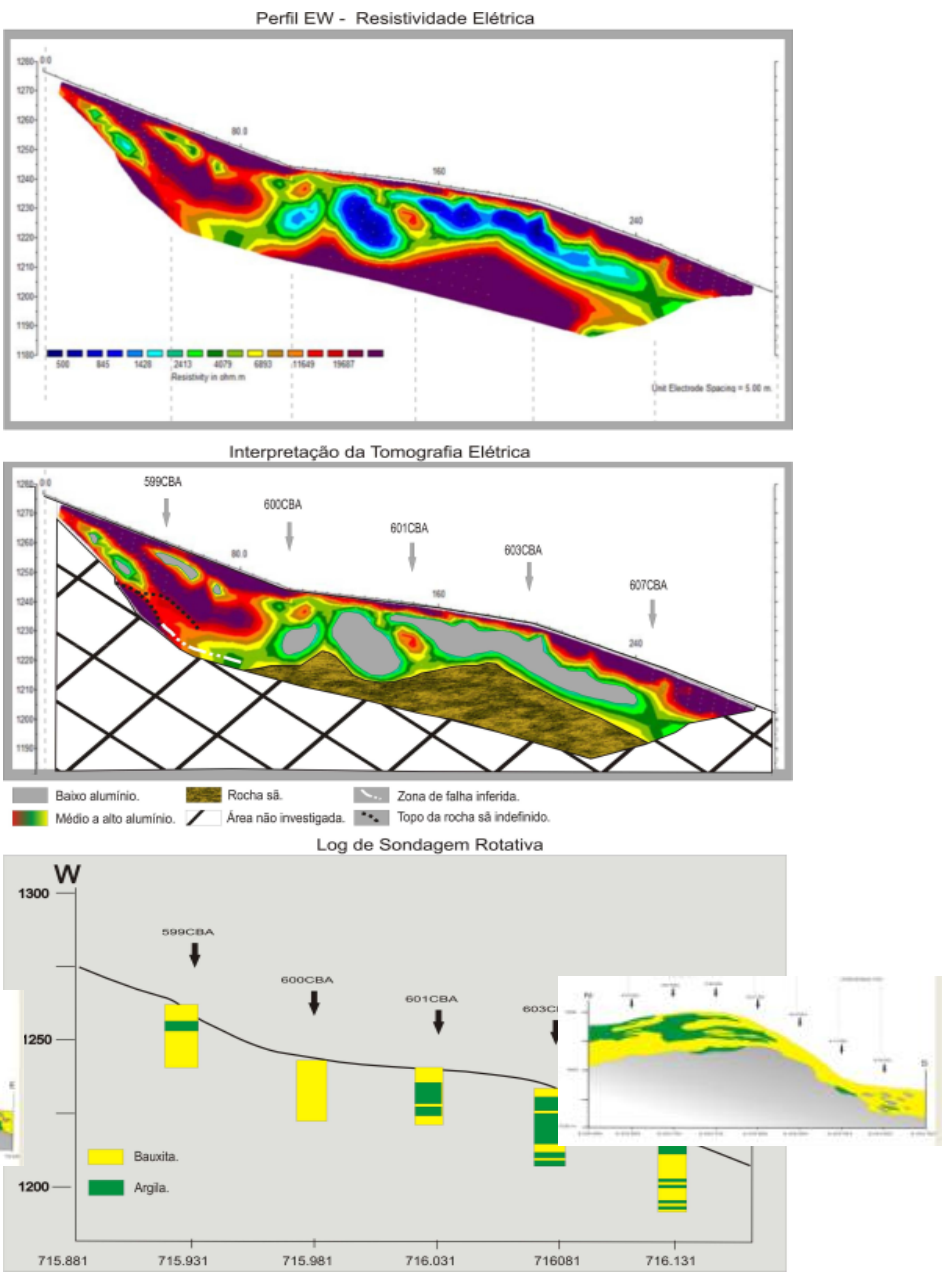

Figura 4-Perfil EW 
O topo da rocha sã está bem delimitado em quase todo o perfil cuja exceção localiza-se próximo a posição 60 devido à profundidade de investigação ter sido subestimada ou à existência de zona de falha.

Quando comparado o perfil geoelétrico interpretado com os logs dos poços percebe-se que há uma divergência com os poços 600CBA e 601CBA localizados na parte central. Acredita-se que tal divergência acontece devido a um erro de posicionamento dos poços em relação ao perfil porque um deslocamento de poucos metros para leste na posição desses poços faz com haja uma boa e coerente correlação com relação entre os logs e o perfil geoelétrico. Para o restante do perfil obteve-se uma coerente correlação com os logs de poços como pode ser observado na delimitação de uma zona argilosa rasa que se encontra descrita no log do poço 599CBA.

\section{Discussão e Conclusões}

O minério de bauxita da Jazida de Barro Alto possui uma ampla diversidade de propriedades físicas análogas a rochas/minérios.

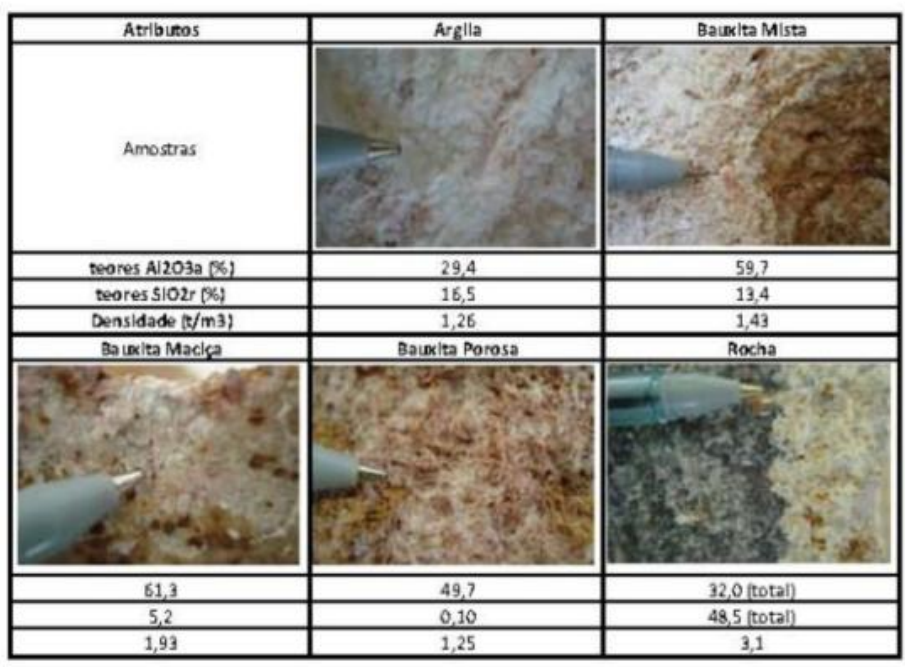

Estabelecendo relação dessas informações com os testes geofísicos por Tomografia Elétrica efetuados em área teste, podemos fazer as seguintes correlações:

\begin{tabular}{|c|c|c|c|c|c|}
\hline TIPOLOGIA & Argila & Bauxita Mista & Bauxita Porosa & Bauxita Maciça & Rocha Sã \\
\hline Densidade & (baixo) $\downarrow$ & intermediária & intermediária & intermediária & 4 (alto) \\
\hline Porosidade & 4 & intermediária & 4 & intermediária & \\
\hline Permeabilidade & 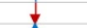 & $\uparrow$ & 4 & $\uparrow$ & $\uparrow$ \\
\hline Condutividade & 4 & $\downarrow$ & $\downarrow$ & $\downarrow$ & 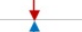 \\
\hline Resistividade & $\downarrow$ & & & & \\
\hline
\end{tabular}

A partir dos dessa correlação, podemos concluir que:

- foi possível determinar os limites entre três diferentes tipos de materiais de interesse prospectivo em subsuperfície, compostos pela bauxita (superficial e em profundidade - alta resistividade); zonas argilosas (baixa resistividade) e rocha sã (alta resistividade);

- o material associado à bauxita está correlacionado com respostas geoelétricas com alta resistividade desde a superfície até profundidades e em zonas intermediárias, onde lateral ou verticalmente estão em contatos com zonas anômalas de baixa resistividade (argilas);

- a resposta geoelétrica resistiva da bauxita, principalmente em superfície até 2 a $3 \mathrm{~m}$ de profundidade está diretamente associado às condições de saturação em água desses níveis. Nova etapa de aquisição de dados deverá ser realizada após o período chuvoso para avaliar de forma mais detalhada qual será a ordem de grandeza da redução da resistividade elétrica desse material.

- é possível associar as zonas argilosas às respostas geoelétricas com baixa resistividade que quando comparada aos dados químicos disponíveis remetem para há existência entre uma relação indireta do baixo conteúdo em alumínio e a diminuição da resistividade elétrica;

- as propriedades físicas dos materiais que puderam ser correlacionados com a técnica de Tomografia Elétrica foram à densidade e a permeabilidade/porosidade;

- a associação com outras metodologias geofísicas de pesquisa pode levar a uma melhor diferenciação quanto à tipologia do minério e a definição com maior detalhe do topo da rocha sã, além da determinação da presença de matacões e bolders de bauxita envoltos de material argiloso. Isto já está sendo observado com as primeiras respostas da sísmica de refração (limite rocha sã) e do radar de penetração do solo;

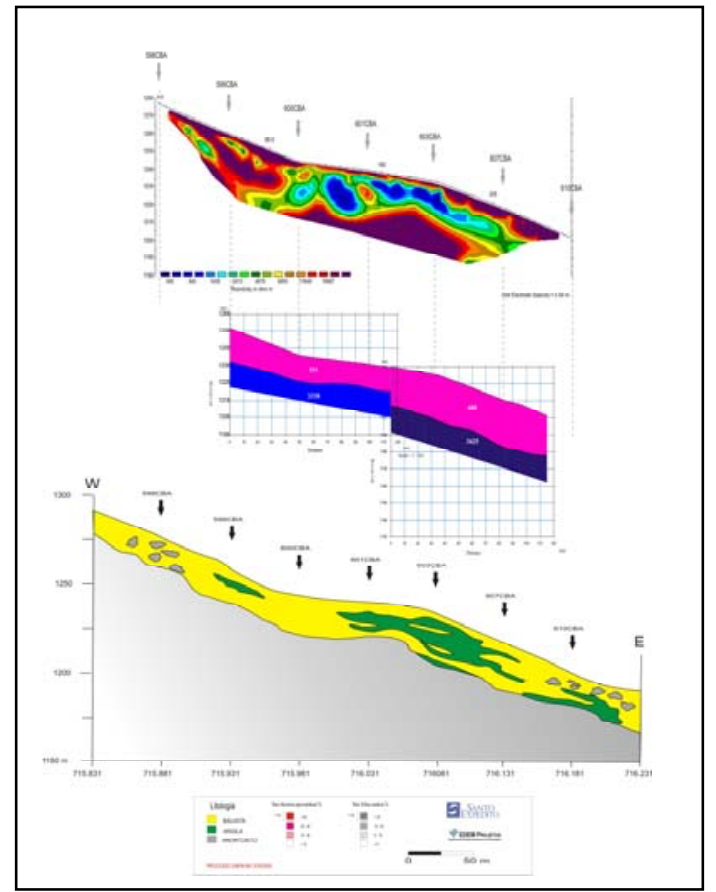

Fig5- Perfil sísmico correlacionado com perfil de Resistividade e IV Simpósio Brasileiro da SBGf - Brasília 2010 Topoqeolóqico 


\section{Agradecimentos}

A todos os profissionais que fizeram parte da equipe de pesquisa.

Referências (Arial Bold, 9) Veja normas da RBGf

ABAL - Associação Brasileira do Alumínio. 2005. Informações diversas sobre alumínio, disponíveis em: www.abal.org.br

ABC - Associação Brasileira de Cerâmica. Anuário Brasileiro de Cerâmica, edições de 2002, 2003 e 2004, São Paulo.

AGIM - Agência Goiana de Desenvolvimento Industrial e Mineral. 2000. Geologia e Recursos Minerais do Estado de Goiás e do Distrito Federal. CPRM / METAGO / UnB, Goiânia, em cd-rom.

ALMEIDA, F.F.M. 1977. O cráton do São Francisco, Rev. Bras. Geociências, 7:349-364.

ARANTES, D.; BUCK, P.S.; OSBORNE, G.A.; PORTO, C.G. 1991. A seqüência vulcano-sedimentar de Mara Rosa e mineralizações associadas. Bol. Informativo SBG Núcleo Centro-Oeste, 14:27-40.

CARVALHO, A.; BOULANGÉ, B.; MELFI, A.J.; LUCAS, Y. (eds.) 1997. Brazilian bauxites. USP / FAPESP / ORSTOM. São Paulo / Paris, 331 p.

CORREIA, C.T. 1994. Petrologia do complexo máficoultramáfico de Cana Brava, Goiás. IG / USP, São Paulo, Dissertação de doutorado, 151 p.

CORREIA, C.T.; JOST, H.; TASSINARI, C.C.G.; GIRARDI, V.A.V.; KINNY, P.D. 1999. Ectasian Mesoproterozoic U-Pb ages (SHRIMP II) for the metavolcano-sedimentary sequences of Juscelândia and Indaianópolis and for high grade metamorphosed rocks of Barro Alto stratiform igneous complex, Goiás State, Central Brazil. In: South American Symp. Isotope Geology, 2, Cordoba, Argentina, Actas, 31-33.

CORREIA, C.T.; TASSINARI, C.C.G.; LAMBERT, D.D.; KINNY, P. D.; GIRARDI, V.A.V. 1997. Sm-Nd and Re-Os systematics of the Cana Brava, Niquelândia and Barro Alto layered intrusions in Central Brazil, and constraints of the tectonic evolution. In: South American Symp. Isotope Geology, 1, Campos do Jordão, Brasil, Actas, 88-89.

COSTA, M.L. 1991. Aspectos geológicos dos lateritos da Amazônia. Rev. Bras. Geociências, 21:146-160.

CPRM - Companhia de Pesquisa de Recursos Minerais. 1972. Projeto Goianésia - Barro Alto. DNPM / CPRM, Goiânia, Relatório Final, 3 vol., anexos.

DANNI, J.C.M. e LEONARDOS, O.H. 1978. As seqüências granulítica, anortosítica-anfibolítica e ultramáfica da região de Niquelândia - GO. Congr. Bras. Geologia, 30, Recife, SBG, Resumos, 1:45.
DANNI, J.C.M. e LEONARDOS, O.H. 1980. The Niquelândia mafic-ultramafic granulites and gabroanortosites metavolcanic associations. IG / UnB, Brasília, inédito (submetido a Precambrian Research).

DANNI, J.C.M.; FUCK, R.A.; LEONARDOS, O.H. 1982. Archean and Lower Proterozoic Units in Central Brazil. Geol. Rundschau, 71(1):291-317.

DARDENNE, M.A. 2000. The Brasília Fold Belt. In: CORDANI, U.G.; MILANI, E.J.; THOMAZ FILHO, A.; CAMPOS, D.A. (eds.). Tectonic Evolution of South America. Intern. Geological Congress, 31, Brazil, Rio de Janeiro, p. 231-263.

DARDENNE, M.A. e SCHOBBENHAUS, C. 2001. Metalogênese do Brasil. Editora UnB, Brasília, 392 p. il.

DNPM - Departamento Nacional de Produção Mineral. 2001. Balanço Mineral Brasileiro 2001 - Alumínio. DNPM, Brasília, 31 p. Disponível em www.dnpm.gov.br

DNPM - Departamento Nacional de Produção Mineral. 2005. O Setor Mineral - Sumário Executivo - 2005. DNPM, Sumário Mineral, v. 25, Brasília, p. 29-30. Disponível em www.dnpm.gov.br

ELLERT, R. 1959. Contribuição à geologia do maciço alcalino de Poços de Caldas, Minas Gerais. IG / USP, Bol. 237, 120 p.

FERREIRA FILHO, C.F. 1998. Geologia e petrologia dos complexos de Barro Alto, Niquelândia e Cana Brava: implicações para a prospecção de platinóides. Congr. Bras. Geologia, 40, Belo Horizonte, SBG, Resumos, p. 140.

FERREIRA FILHO, C.F. e NALDRETT, A.J. 1993. The Niquelândia mafic-ultramafic complex revisited: tectonic setting and potential for PGE deposits. Brazilian PGE Metg., Extended Abstracts, p. 25-28.

FERREIRA FILHO, C.F. e PIMENTEL, M.M. 2000. Sm$\mathrm{Nd}$ isotope systematics and REE-Hf-Ta-Th data of troctolites and their amphibolitized equivalents of the Niquelandia Complex upper layered series, central Brazil: further constraints for the timing of the magmatism and high-grade metamorphism. Jour. South Am. Earth Sci. 13, 647-659.

FERREIRA FILHO, C.F.; KAMO, S.; KROGH, T.; NALDRETT, A.J. 1992. U-Pb geochronology of the Niquelândia layered mafic-ultramafic intrusion, Brazil: constraints for the timing of magmatism and grade metamorfism. Edmonton '93 Abstracts.

FUCK, R. A. et al. 1981. Geologia da região de Goianésia. Simp. Geol. Centro-Oeste, 1, Goiânia, SBG Núcleos Centro-Oeste e Brasília, Ata..., p. 447-467.

FUJI, M. 1989. REE geochemistry and Sm-Nd geochronology of the Cana Brava complex, Brazil. Univ. Kobe, Master thesis, $55 \mathrm{p}$. 
GIRARDI, V.A.V.; RIVALENTI, G. e SINIGOLFI, S. 1986. The petrogenesis of the Niquelandia layered basicultrabasic complex, Central Goias, Brazil. Journal of Petrology, 27(3):715-744

KOUTSCHOUBEY, B. 1988. Geologia do Alumínio. In: SCHOBBENHAUS, C. e COELHO, C.E.S. (coords.). Principais Depósitos Minerais do Brasil. DNPM, Brasília, vol. 3, p. 599-619.

MELFI, A.J. e CARVALHO, A. 1983. Bauxitization of alcaline rocks in Southern Brazil. Scienc. Geol. Mem., 73:161-172.

MELFI, A.J. et al. 1991. Mobilidade do zircônio na bauxitização de rochas alcalinas do maciço de Poços de Caldas, MG. Rev. Bras. Geociências, 21(1):17-22.

MORAES, R.; FUCK, R.A.; PIMENTEL, M.M.; GIOIA, S.M.C.L. e FIGUEIREDO, A.M.G. 2003. Geochemistry and $\mathrm{Sm}-\mathrm{Nd}$ isotope characteristics of bimodal volcanic rocks of Juscelândia, Goiás, Brazil: Mesoproterozoic transition from continental rift to ocean basin. Precambrian Res. 125: 317-336.

OLIVEIRA, A.M. 1993. Petrografia, estratigrafia, petroquímica, e potencialidade para elementos do grupo da platina (EGP) do Complexo de Barro Alto, na região de Goianésia, Goiás. UnB, IG, Brasília, dissertação de mestrado, $86 \mathrm{p}$.

PARISI, C.A. 1988. Jazidas de bauxita da região de Poços de Caldas, Minas Gerais. In: SCHOBBENHAUS, C. e COELHO, C.E.S. (coords.). Principais Depósitos Minerais do Brasil. DNPM, Brasília, vol. 3, p. 661-666.

PIMENTEL, M.M.; LAUX, J.H.; ARMELE, A.; FERREIRA FILHO, C.F. 2005. Idade dos complexos máficoultramáficos de Barro Alto, Niquelândia e Canabrava, Goiás. Goiânia,SBG - Núcleo Centro-Oeste, Simp. Geol. Centro-Oeste, 9, Resumos, p. 108-109.

PIMENTEL, M.M; FUCK, R.A.; JOST, H.; FERREIRA FILHO, C.F e ARAUJO, S.M. 2000. The basement of the Brasília Fold Belt and the Goiás Magmatic Arc. In: CORDANI, U.G.; MILANI, E.J.; THOMAZ FILHO, A.; CAMPOS, D.A. (eds.). Tectonic Evolution of South America. Intern. Geological Congress, 31, Brazil, Rio de Janeiro, p. 195-229.

RADAMBRASIL. 1981. Levantamento de Recursos Naturais, Folha SD.22 Goiás. Projeto Radambrasil, Rio de Janeiro, vol. 25, 640 p., mapas.

REED, J. 1995. Principles of Ceramics Processing. John Willey \& Sons, New York, pp. 42, 71-72.

Revista Industrial Minerals. Edições de abril, maio e junho de 2005.

RIVALENTI, G.; GIRARDI, V.A.V.; SINIGOLFI, S.; ROSSI, A.; SIENA, F. 1982. The Niquelandia maficultramafic complex of Central Brazil: petrological considerations. Rev. Bras. Geociências, 12:380-391.
SANTOS, P.S. 1975. Bauxitas e Argilas para Fabricação de Alumina e Alumínio. In: Tecnologia de Argilas, v. 2, cap.15, Ed. Edgard Blucher, São Paulo.

SHREVE, R.N. \& BRINK Jr, J.A. 1977. Chemical Process Industries. McGraw-Hill, New York.

SILVA, M.L.M.C. e OLIVEIRA, S.M.B. 1992. Caracterização mineralógica e química das bauxitas de Nazaré Paulista (SP). Rev. Bras. Geociências, 22(1):9399.

USGS - United States Geological Survey. 2005. Informações do governo dos EUA sobre produção, consumo e evolução dos preços de bauxita. Disponível em: http://minerals.usgs.gov

VEIGA, A. T. C. 1999. A geodiversidade e o uso dos recursos minerais da Amazônia. Terra das Águas, NEAz I UnB, Brasília, 1:88-102.

VEIGA, A. T. C. 2002. Breve história geológica de Goiás. In: BERTRAN, P. (ed.). Goiás: 1722 - 2002. Agência Goiana de Cultura, Goiânia, p. 18-22. 